University of St. Thomas, Minnesota

UST Research Online

The Impact of Deceitful Tendencies, Relativism and Opportunism

on the Negotiation Tactics: A Comparative Study of U.S. and Belgian Managers

\author{
Jamal Al-Khatib \\ University of St. Thomas, Minnesota, jaalkhatib@stthomas.edu \\ Avinash Malshe \\ University of St Thomas, amalshe@stthomas.edu \\ John Sailors \\ University of St.Thomas, Minnesota, jjsailors@stthomas.edu \\ Irvin Clark \\ James Madison University
}

Follow this and additional works at: https://ir.stthomas.edu/ocbmktgpub

Part of the Marketing Commons

This Article is brought to you for free and open access by the Marketing at UST Research Online. It has been accepted for inclusion in Marketing Faculty Publications by an authorized administrator of UST Research Online. For more information, please contact asle4660@stthomas.edu. 


\title{
The impact of deceitful tendencies, relativism and opportunism on negotiation tactics: a comparative study of US and Belgian managers
}

Jamal A. Al-Khatib, Avinash Malshe and John J. Sailors Opus College of Business, University of St Thomas, St Paul, Minnesota, USA, and

Irvin Clark III

College of Business, James Madison University, Harrisonburg, Virginia, USA
Deceitful tendencies

Received March 2008 Revised May 2008 Accepted June 2009

\begin{abstract}
Purpose - The purpose of this paper is to compare the antecedents of opportunism and its effect on unethical negotiation tactics among US and Belgian managers.

Design/methodology/approach - Samples of managers in both countries are surveyed and cross-country analysis using multi-group structural equation modeling is conducted.

Findings - Across both countries, deceitful tendencies and relativism are found to be significant predictors of opportunism, which in turn predicts receptiveness to unethical negotiating tactics; however, Belgian managers were found to have higher levels of these constructs, possibly indicating a greater propensity to engage in unethical behaviors than US managers.

Research limitations/implications - The current research is limited by the relatively small size of the Belgian sample, differences in data collection method, and the lack of additional contextual measures, which may influence the managers' responses.

Practical implications - The finding that the same structural relationships hold across the US and Belgium samples provides insights for both groups of managers engaged in negotiations.

Originality/value - The paper offers a comparative perspective on US and Belgian managers and establishes the validity and applicability of frequently used ethics scales in Belgium, a country infrequently studied in this context.
\end{abstract}

Keywords United States of America, Belgium, Managers, Negotiating, Ethics

Paper type Research paper

\section{Introduction}

Negotiation has been defined as "a process of potentially opportunistic interaction by which two or more parties, with some apparent conflict, seek to do better through jointly-decided action than they could otherwise" (Lax and Sebenious, 1986, p. 11). It is a tactical process, potentially littered with ethical dilemmas as each party seeks to maximize their own outcomes.

Instances of unethical behaviors have muddied the negotiation process across the globe ("Global anti-corruption drive", International Construction, 2004; African Business, 2004, "Lesotho corruption appeal backfires"). It thus becomes imperative for business managers to understand the ethical mindsets of their global negotiation partners (Bagozzi, 1995). In the negotiation ethics literature, barring a few exceptions

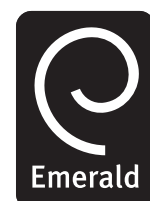

European Journal of Marketing Vol. 45 No. 1/2, 2011 pp. $133-152$

(C) Emerald Group Publishing Limited 0309-0566 
EJM

$45,1 / 2$

134

(e.g. Malshe et al., n.d.), little explicit attention has been devoted to opportunism in negotiation (Robinson et al., 2000) and scarce guidance exists for US managers on how to deal with the ethical components of global negotiations.

A case in point is the heightened need for American negotiators to understand the ethical perspectives of Belgian managers; given Belgium's rank as the 11th-largest market for the export of US goods and services (CIA World Factbook, 2007), the possibility of expansion in this trade partnership, and the lack of extant knowledge about Belgian negotiation ethics. Further, Belgian managers' poor reputation may inhibit US managers' willingness to seek closer relationships with them (Helper and Levine, 1992) and absent any comparative assessment, Belgians may project their self-perceptions to their US counterparts and suspect US managers as also being untrustworthy partners (Sakalaki et al., 2007).

Since little prior empirical research has focused on the negotiation ethics of Belgian managers, this paper draws on the findings from extant empirical studies and models opportunism as arising from intrinsically ethical orientations. Specifically, this paper aims to compare and contrast:

- the role of relativism and deceitful tendencies as antecedents of opportunism; and

- how opportunism impacts managers' perception of unethical negotiation tactics in the US and Belgian contexts.

This paper's contribution lies in:

- positioning opportunism as an unrestrained self-interest maximization (with guile) that may emerge to the fullest extent feasible and profitable in the competitive negotiation process (Bonoma, 1976);

- highlighting how relativism and deceitful tendencies may serve as antecedents of opportunism both in the US and Belgian contexts;

- comparing the relationships between deceitful tendencies, relativism, opportunism and unethical negotiation tactics that Malshe et al. (forthcoming) showed in the US context with that in the Belgian context;

- validating the various business ethics scales in the Belgian context; and

- contributing to the divergence/convergence debate in a global context.

\section{Constructs and conceptual domains}

We treat opportunism as "self-interest seeking with guile" (Williamson, 1975). Our definition is consistent with John's (1984) explication of this concept as shirking, or failing to fulfill promises and obligations. Relativism (Forsyth, 1980) reflects the individual's rejection of universal moral principles. Deceitful tendencies are defined as "the intention of creating or adding support to a false belief in another party" (Cramton and Dees, 1993), and is operationalized as the propensity to lie since it "benefits the communicator" (Triandis, 2001). While opportunism represents failing to fulfill promise, deceitful tendencies represent a propensity to lie and create a false belief in other party. The five unethical negotiation tactics are:

(1) Inappropriate information gathering.

(2) Misrepresentation of information.

(3) Traditional competitive bargaining. 
(4) Attacking negotiating opponent's network.

(5) Making false promises (Lewicki and Robinson, 1998).

In this paper, we treat the executives' perceptions regarding the appropriateness of using the previous five unethical negotiation tactics as outcome variables.

\section{Literature review and hypotheses}

\section{Opportunism}

Opportunism (Williamson, 1975) has been one of the more provocative concepts in the management literature. While self-interest seeking has long been a cornerstone of economics and management, Williamson notes that it need not be pursued honestly; rather, people may look after their interests while trying to skirt or break the rules or norms of behavior. Specifically, Williamson (1975) defines opportunism as "self-interest seeking with guile".

Research shows that opportunistic behavior can have a crippling effect on exchange in the form of decreased efficiency and inequitable distribution. Thus, managing opportunism so that exchange partners deliver on agreed-on obligations is a major challenge in conducting global business (Aulakh et al., 1996), and investigating its impact on exchange partners' perceptions of unethical negotiation practices should be beneficial, both domestically and internationally.

While scholars (Wathne and Heide, 2000; Stump and Heide, 1996) exhort that opportunism must be minimized during transactions, they have not extensively studied the impact of opportunism in the negotiation ethics context. Hunt and Morgan (1995) suggest that people's tendency to act opportunistically should be explored and not assumed while Williamson himself notes that not all agents should be regarded as opportunistic in identical degree. Implicit in Williamson's treatment of the construct's variability is the suggestion that it has antecedents, that it is, in fact, an endogenous variable. Prior research has not typically treated opportunism as an endogenous variable; some exceptions involve understanding the organizational and environmental factors that may impact it (e.g. John, 1984; Joshi and Arnold, 1997). We hypothesize and test the role of other factors intrinsic to the individual.

\section{Ethical orientation (relativism) and opportunism}

Individuals use ethical guidelines based on one of two moral philosophies: deontological and teleological (Hunt and Vitell, 1986). Deontological philosophy focuses on the specific actions or behaviors of an individual, whereas teleological philosophy focuses on the consequences of the actions. This paradigm is parallel to Forsyth's (1980) two-dimensional personal moral philosophies concept idealism/relativism. Specifically, idealism, which parallels the deontological perspective, describes the degree to which individuals understand actions as right or wrong and believe that a "right" decision can be made in an ethically tenuous situation, keeping in mind others' welfare when evaluating alternatives. Less idealistic individuals may make decisions irrespective of its impact on others. Relativism, not an opposite, but a separate dimension, is the degree to which an individual rejects universal moral norms in making ethical judgments. High relativists make decisions on a situation-specific basis while low relativists believe that standard rules can be 
EJM

$45,1 / 2$

136 applied across situations. Forsyth (1992) suggested that individuals' ethical ideologies should have an impact on how he/she would handle ethically challenging situations.

We argue that when people will face situations where their perceived self-interests run contrary to operational norms, individuals low on relativism will most likely sacrifice self-interest for the sake of said norms. A relativist, in contrast, will not be as willing to forgo their narrow interests. First, relativists do not believe in absolute moral values and apply different sets of rules while interpreting and responding to different situations. This may provide relativists with greater flexibility in interpreting situations and allow them to respond in a manner that best suits their needs. Second, a relativistic orientation affords individuals the freedom to justify their moral judgments and responses and not be "constrained" by the need to maintain consistency in varying circumstances. Self-interest seeking relativists may not be able to truly maximize self-interest without being willing rejecting external norms (Bonoma, 1976).

That relativistic tendencies are strongly related to opportunism has found empirical support. Malshe et al. (n.d.) show how opportunism acts as an explicit mediator within the relationship between relativism and perceptions of unethical negotiation tactics. Rawwas et al. (2004), found that, among the US, and, Chinese marketing students, those who were least critical of academic dishonesty tended to score highly on both relativism, and opportunism. Similarly, Rawwas et al. (2006) found that students at a Japanese religious university were most likely to attribute unethical behavior to people perceived to score highly on relativism and opportunism.

Based on the previous discussion, we hypothesize:

H1. Relativism is positively related to opportunism.

\section{Deceitful tendencies and opportunism}

Deception in negotiation has long been a topic of concern in business ethics (Christie and Geis, 1970). Deception involves "the intention of creating or adding support to a false belief in another party" (Cramton and Dees, 1993). Mitchell (1986) defines deception as "a false communication that tends to benefit the communicator". Deceit has been viewed as a component of the larger, multidimensional construct of Machiavellianism (Hunter et al., 1982), which examines the individual's opinions regarding lying and honesty; and as a component of manipulativeness that amounts to lying and cheating to get what one wants. People who tend to score highly on Machiavellianism practice manipulative acts with detachment and perceive little guilt when lying. Withholding or distorting information, shirking and failing to fulfill promises or obligations are also examples of deceitful behavior.

The objective behind deceitful behavior by a partner firm during negotiation is to seek gain at the expense of its negotiation opponent. Negotiators face uncertainty about the other party's goals and intentions, which, combined with the competitive nature of negotiation, produces a ripe environment for protecting one's personal interest (Ferrell and Gresham, 1985; Hagarty and Sims, 1978). This may be achieved by controlling the amount and accuracy of information revealed to the other party- a manifestation of deceit.

Scholars have largely focused on understanding either the reasons for deception or its frequency. While previous research (Scott and Jehn, 1991) focused on the situational and the target factors that lead to lying, it also acknowledges that people differ in their deceitful tendencies. For example, the business ethics literature suggests that the 
characteristics of the individual and the situation both affect the likelihood to engage in deceit (Hagarty and Sims, 1978).

We continue in this direction and conceptualize deceitful tendencies as a personality characteristic that varies across individuals. We draw on our discussion of the previous literature as well as on Malshe et al. (n.d.) to argue that deceitful tendencies impact the perceptions of unethical negotiation tactics via giving rise to opportunism. Based on the extant theoretical rationale and empirical evidence, we hypothesize that a negotiator's deceitful tendencies are positively related to his/her opportunistic behavior.

H2. Deceitful tendencies are positively related to opportunism.

\section{Opportunism and unethical negotiation tactics}

The context of negotiations provides a fertile ground in which to explore the concept of opportunism. As Lewicki and Stark (1996) have noted, effective negotiators arguably cannot be fully candid about their preferences and positions. While widely studied in marketing and management, opportunism has not received wide attention in the ethics literature.

Lewicki and Stark (1996) and Lewicki and Robinson (1998) have identified five types of unethical negotiating tactics as highlighted earlier- inappropriate information gathering, information misrepresentation, competitive bargaining, attacking the opponent's network, and making false promises. While there is substantial theoretical and empirical evidence suggesting that opportunism and unethical negotiation tactics are independent constructs other research suggests a positive relationship between opportunism and the perception of unethical issues. Specifically, individuals scoring high on the opportunism scale are likely to behave unethically (Al-Khatib et al., 2007; Hunt and Chonko, 1984). Further, Al-Khatib et al. (2008), compared US and Arab executives' negotiation ethics finding that opportunism showed a significant positive effect on the perceptions of all of the unethical negotiation tactics in the US sample whereas in the Arab sample, it had a significant relationship with inappropriate information gathering, information misrepresentation, and making false promise and a marginally significant relationship with the remaining two outcomes. Malshe et al. (n.d.) have also shown a positive relationship between opportunism and the five unethical negotiation tactics.

Opportunists perceive unethical negotiation tactics as acceptable because they may believe it is appropriate to use any means to accomplish personal and organizational goals, including manipulation, and persuasion (Hunt and Chonko, 1984). Newstead et al. (1996) find that cheaters rationalize their behavior by blaming it on the situation rather than themselves, and, as noted earlier, negotiations provide an ideal situation to which to attribute blame.

Based on the previous, we hypothesize the following:

H3. Higher levels of opportunism will result in greater propensity to engage in each type of unethical negotiation tactic.

Figure 1 presents the hypothesized relationships among our constructs.

\section{Comparison between the US and Belgian contexts}

In this section, we argue that the relationships we hypothesized previously will hold true both in the US and Belgian contexts. In both collectivist and individualist societies,
Deceitful tendencies

137 
EJM

$45,1 / 2$

\section{8}

Figure 1.

Conceptual model

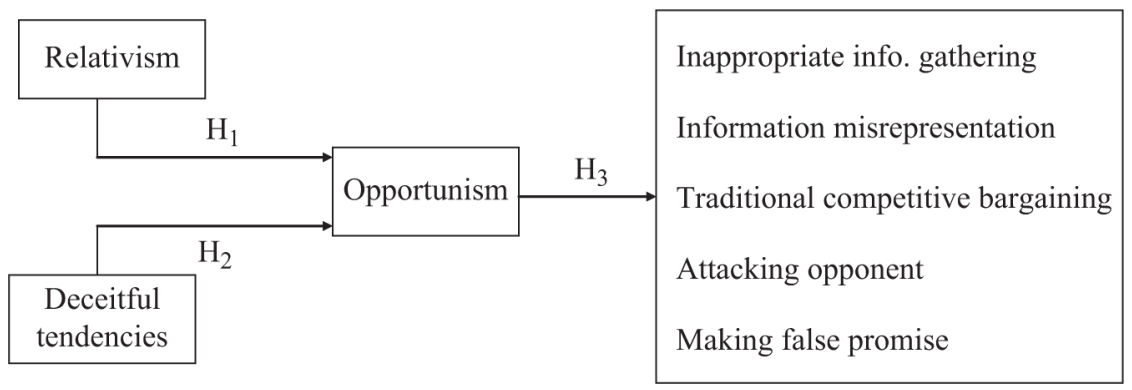

deception, opportunism and unethical behaviors have the potential to damage one's relation with a negotiation partner. In collectivist cultures, like Belgium (Hofstede, 1980), the parameters for opportunistic behavior, deception, rejection of absolute moral rules and unethical behaviors are based on group membership of the negotiating partners and norms present within a specific social/cultural context. In individualistic cultures, like the US, personal relationships and the interest in these relationships dominate.

Therefore both collectivistic (Belgium) and individualistic (US) cultures have appropriate mechanisms to guard against the display of unethical behavior. It is therefore that we hypothesize that the magnitudes of the heretofore hypothesized relationships do not differ across the US and Belgian cultural contexts:

H4. The magnitude of the relationships of relativism and deceitful tendencies to opportunism, and of opportunism to the negotiation tactics will not differ between US, and Belgian managers.

\section{How cultural differences impact ethical ideology and behavior}

While we have argued that the strength of relationships between relativism, deceitful tendencies and opportunism and opportunism and perceptions of unethical negotiation tactics will not differ across the two cultures, we argue that the US and Belgian managers will differ from one another on the extent to which they exhibit relativism, deceitful tendencies, opportunism, and their perceptions of each of the unethical negotiation tactics. First, scholars (Al-Khatib et al., 2005a, b; Vitell et al., 1993) suggest that cultural variations may manifest in differences in individuals' ethical orientations. Further, Hunt and Vitell $(1986,1992)$ propose that "cultural norms affect perceived ethical situations, perceived alternatives, perceived consequences, deontological norms, probabilities of consequences, desirability of consequences and importance of stakeholders" (p. 10). This indicates that when it comes to ethical orientations, managers from different cultures will exhibit differences.

Second, Hofstede (1980) places the USA and Belgium differently along the four cultural dimensions. The USA is low on power distance, low on uncertainty avoidance, moderate on masculinity/femininity, and high on individualism. In contrast, Belgium scores moderately on power distance, is high on uncertainty avoidance, low on masculinity, and moderately high on individualism dimension. It is plausible that opportunism may be less likely in low power distance cultures such as the USA owing to natural power sharing and more participative and consultative decision-making. On 
the contrary, the uses of power and coercion may be frequent occurrences in the relatively higher power-distance Belgian culture (Kale and McIntyre, 1991). Previous studies have reported a positive relationship between power distance and unethical behavior such as taking advantage of the underclass (Husted, 1999; Volkema, 2004). In summary, high power distance represents unequal power distribution and limited interaction between social classes (Volkema and Fluery, 2002), providing an atmosphere conducive for individuals to lie and serve their own means, be opportunistic, and exhibit greater acceptance of such tactics.

Third, previous studies have found that the perceptions among other Europeans of the ethics of Belgian managers are often poor (Jeurissen and van Luijk, 1998; Van Kenhove et al., 2001). Aaccording to Transparency International, Belgium fairs poorly on the scale of corruption (Van Kenhove et al., 2001). Jeurissen and van Luijk (1998) found Belgian managers to rank in the lower tier of European countries on ethical business conduct and on the quality of business relations while the ethical conduct and the quality of business relations with US managers was rated quite positively.

In summary, higher power distance within the Belgian context may allow Belgian managers greater flexibility to engage in opportunistic behavior, lie, and act unethically in an attempt to look out for their self-interest. Further, collectivism may motivate them to be suspicious and distrustful of their negotiating counterparts, who may be treated as outsiders, thereby engaging in greater opportunism, lying, and unethical practices; something that individualist US manager may not be prone to. In addition, evidence from extant research has shown that perceptions regarding ethics of Belgian managers are poor. We hypothesize:

H5. US managers will have lower relativism scores than their Belgian counterparts.

H6. US managers will exhibit lower deceitful tendencies than their Belgian counterparts.

H7. US managers will be less opportunistic than their Belgian counterparts

H8. Belgian mangers will have higher levels of endorsement than their US counterparts for each type of questionable negotiation tactic.

\section{Methodology}

Sampling and data collection

We collected data in the USA and Belgium. While data collection methods differed between countries, our sample shared common characteristics in terms of industries represented (banking, advertising, health care, manufacturing, and trading), positions held (marketing managers or senior marketing executives), and job function (negotiating and contracting with external entities). We asked all responders to reflect on a major contract they negotiated within the past one-year, while answering our survey.

In the USA, data were collected as described in Malshe et al. (n.d.). Specifically e-mails with a survey link embedded within were sent to the Institute for Supply Management's (ISM) 3,200 US-based members, with a reminder after one week. We guaranteed respondent anonymity. A total of 466 ISM members clicked on the
Deceitful tendencies

139 
EJM

$45,1 / 2$

140

active survey link and 259 individuals completed the questionnaire, resulting in an overall response rate of 12.1 percent, which compares favorably to some other published studies (e.g. Ranchhod and Zhou, 2001). We compared early (response within a week) and late responders (response after reminder) to test for non-response bias and did not find significant difference (Armstrong and Overton, 1977).

Owing to the lack of mailing lists in Belgium, we used General Business Directory in Antwerp for identifying 200 potential respondents. On their consent to participate, we gave them basic procedural instructions; the English language survey was hand-delivered in the morning, and picked-up at the end of the same workday. This resulted in an operational data set of 153 respondents, for a response rate of 76 percent. The data collection in Belgium occurred immediately after the data collection in the USA. A comparison between respondents and non-respondents in Belgium did not reveal any significant differences; hence, non-response bias was not an issue in Belgium. Table I summarizes the demographic characteristics of the two samples.

\section{Survey instrument}

Our measure of relativism was taken from the Ethics Position Questionnaire (EPQ) (Forsyth, 1980) and was purified, leaving seven of the original ten items. Opportunism was measured using a five item five-point Likert scale (Dwyer and Oh, 1988). Deceitful tendencies were measured using a portion of the MACH IV scale (Christie and Geis, 1970) that comprises three reverse-coded items. Last, we measured perceptions of unethical negotiation tactics using the Self-Reported Inappropriate Negotiation Strategies Scale (SINS scale) (Robinson et al., 2000). Tables II and III show the scale items.

\section{Data analysis}

We assessed the internal consistency of our measures using Cronbach's alpha. While most composite reliabilities were above 0.70 (Nunnally, 1978), an exception was the Relativism and Deceitful Tendencies scales. As mentioned earlier, we purified the Relativism scale, and yet, it had a marginal reliability. The reliability for the Deceit scale is marginal as well. Scholars have noted the difficulty in finding scales that work well cross-culturally; hence, scale reliability of less than 0.70 in some countries should not be considered unusual (Nunnally, 1978). Table IV presents pertinent scale statistics.

Table I.

Demographic characteristic of the samples

\begin{tabular}{lll}
\hline & The USA & Belgium \\
\hline Gender & & \\
$\quad$ Male (\%) & 80 & 61 \\
Female (\%) & 20 & 39 \\
Education & Over 90 percent with college degree & 79 percent with college degree \\
Company size & & \\
$\quad<250$ employees (\%) & 42 & 35 \\
$>250$ employees (\%) & 58 & 65 \\
Years in current position & Nine years & 5.8 years \\
\hline
\end{tabular}




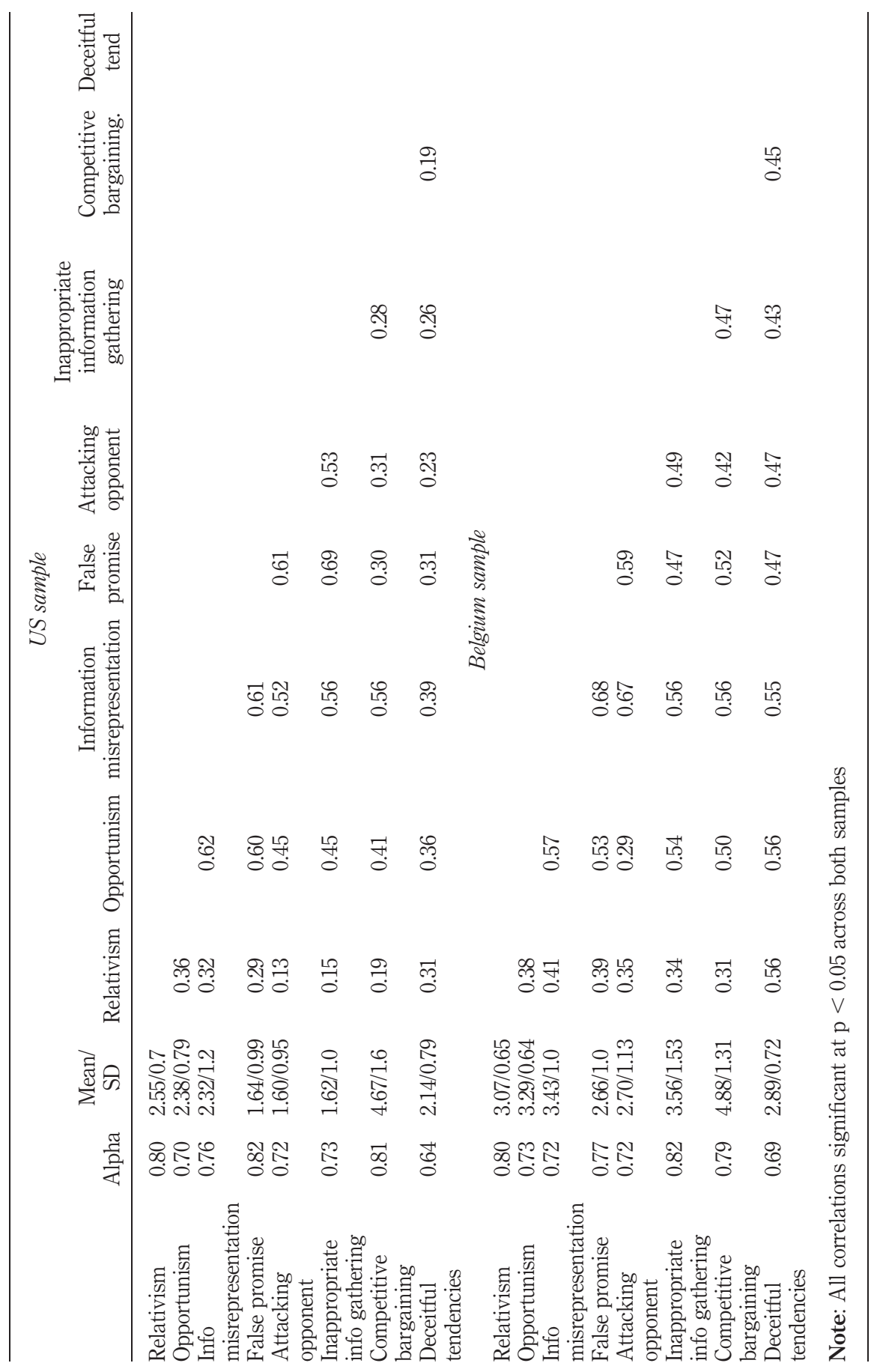

Deceitful
tendencies

141

Table II. Cronbach's alphas, descriptive statistics, and correlation matrix 
EJM

$45,1 / 2$

142
Configural and measurement invariance

Since our scales had not been tested in Belgian context before, we wanted to establish their configural and measurement invariance across the two country samples first (Horn and McArdle, 1992). Accordingly, we used EQS (Bentler, 1992) to conduct a multi-group confirmatory factor analysis (CFA) for each country with no cross-country constraints imposed (Byrne, 2003). The results of these models and the fit statistics are also shown in Tables II and III. All factor loadings were significant. Further, fit indices such as CFI of 0.989 and the Bentler non-Normed Fit Index (BNNFI) of 0.988 indicate that the model had an acceptable fit across both countries. This provides evidence that our constructs can be conceptualized in the same way across the two countries (Steenkamp and Baumgartner, 1998).

To test for measurement invariance, we assessed whether:

- the items comprising the measuring instruments operate equivalently;

- factorial structure of each construct is equivalent; and

- paths in the specified causal structure are invariant across two countries (Byrne, 2003; p. 159).

Specifically, we constrained parameters in a logically ordered and increasingly restrictive fashion. We first constrained factor loadings paths. Next, we added constraints on factor variances followed by finally adding constraints on factor covariances. All the previous tests resulted in acceptable model fits indicating cross-country invariance on our measures (see Table V). Thus, we can be confident that scores on items, can be meaningfully compared across countries and that observed item differences are indicative of similar cross-national differences in the underlying construct.

Next, we evaluated convergent and discriminant validity. Specifically, we tested whether the correlations among constructs significantly departed from 1.0. This was the first criterion for establishing discriminant validity. Further, with the exception of one item in our revised Relativism scale ("there are no ethical principles that are so important that they should be a part of any code of ethics"), no other items were found to cross-load on other constructs thus satisfying the second criteria used by Calantone et al. (2006). We decided to retain this problematic item owing to its conceptual importance as well as its inter-item and item-to-total correlation with the relativism scale. We also conducted paired tests of all the constructs in order to ascertain that they

\begin{tabular}{lcrrrr}
\hline & \multicolumn{2}{c}{ The USA } & \multicolumn{2}{c}{ Belgium } \\
& CR & AVE & CR & AVE \\
\hline Relativism & 0.73 & 0.29 & 0.77 & 0.34 \\
Deceit & 0.62 & 0.37 & 0.59 & 0.34 \\
Opportunism & 0.65 & 0.39 & 0.69 & 0.42 \\
Inappropriate information gathering & 0.73 & 0.48 & 0.80 & 0.59 \\
Information misrepresentation & 0.76 & 0.44 & 0.71 & 0.39 \\
Competitive bargaining & 0.81 & 0.58 & 0.80 & 0.57 \\
Attacking opponent network & 0.67 & 0.51 & 0.76 & 0.62 \\
Making false promises & 0.82 & 0.61 & 0.77 & 0.55 \\
& & & & &
\end{tabular}

\section{Table III.} Construct Reliability (CR) and Average Variance Extracted (AVE) 


\begin{tabular}{|c|c|c|c|c|c|}
\hline \multirow[b]{2}{*}{$\begin{array}{l}\text { Construct } \\
\text { Items }\end{array}$} & \multicolumn{2}{|c|}{ The USA } & \multicolumn{2}{|c|}{ Belgium } & \multirow{2}{*}{$\begin{array}{l}\text { Deceitful } \\
\text { tendencies }\end{array}$} \\
\hline & $\begin{array}{l}\text { Std. } \\
\text { loading }\end{array}$ & $(t \text {-value })^{*}$ & $\begin{array}{l}\text { Std. } \\
\text { loading }\end{array}$ & $(t \text {-value })^{*}$ & \\
\hline \multicolumn{6}{|l|}{ Relativism } \\
\hline $\begin{array}{l}\text { There are no ethical principles that are so important } \\
\text { that they should be a part of any code of ethics }\end{array}$ & 0.36 & 4.75) & 0.28 & 3.30) & \\
\hline $\begin{array}{l}\text { What is ethical varies from one situation and } \\
\text { society to another }\end{array}$ & 0.60 & 8.50 & 0.47 & 5.71 & \\
\hline $\begin{array}{l}\text { Different types of moralities can not be compared } \\
\text { as to "rightness" }\end{array}$ & 0.41 & 5.46 & 0.58 & 7.29 & \\
\hline $\begin{array}{l}\text { What is ethical for everyone can never be resolved } \\
\text { since what is moral or immoral is up to the } \\
\text { individual }\end{array}$ & 0.64 & 9.18) & 0.81 & 11.21 & \\
\hline $\begin{array}{l}\text { Moral standards are simply personal rules which } \\
\text { indicate how a person should behave, and are not to } \\
\text { be applied in making judgments of others }\end{array}$ & 0.51 & 6.95 & 0.76 & 10.29 & \\
\hline $\begin{array}{l}\text { Ethical considerations in interpersonal relations are } \\
\text { so complex that individuals should be allowed to } \\
\text { formulate their own individual codes }\end{array}$ & 0.62 & 8.79 & 0.58 & 7.32 & \\
\hline $\begin{array}{l}\text { Rigidly codifying an ethical position that prevents } \\
\text { certain types of actions stands in the way of better } \\
\text { human relations and adjustments } \\
\text { Deceitful tendencies }\end{array}$ & 0.54 & 7.50 & 0.43 & 5.25 & \\
\hline $\begin{array}{l}\text { Honesty is the best policy in all cases (reverse } \\
\text { coded) }\end{array}$ & 0.67 & 8.74 & 0.66 & 8.28 & \\
\hline $\begin{array}{l}\text { There is no excuse for lying to someone else } \\
\text { (reverse coded) }\end{array}$ & 0.69 & 8.99 & 0.39 & 4.69 & \\
\hline $\begin{array}{l}\text { When you ask someone to do something for you it } \\
\text { is best to give the real reasons for wanting it rather } \\
\text { than giving reasons which carry more weight } \\
\text { (reverse coded) } \\
\text { Opportunism }\end{array}$ & 0.43 & 5.50 & 0.65 & 8.17 & \\
\hline $\begin{array}{l}\text { You may promise your negotiation counterpart to } \\
\text { do something without actually doing it later }\end{array}$ & 0.77 & 12.09 & 0.55 & 6.51 & \\
\hline $\begin{array}{l}\text { Sometimes you may have to alter the facts slightly } \\
\text { in order to get what you need from your negotiation } \\
\text { counterpart }\end{array}$ & 0.44 & 6.19 & 0.71 & 8.76 & \\
\hline $\begin{array}{l}\text { Occasionally you will shirk certain negotiated } \\
\text { agreements/obligations when you see profitable } \\
\text { opportunities from doing so } \\
\text { Inappropriate information gathering }\end{array}$ & 0.62 & 9.22 & 0.69 & 8.56 & \\
\hline $\begin{array}{l}\text { Gain information about an opponent's negotiating } \\
\text { position by paying your friends, associates, and } \\
\text { contacts to get this information for you }\end{array}$ & 0.61 & 9.32 & 0.77 & 10.59 & \\
\hline $\begin{array}{l}\text { Gain information about an opponent's negotiating } \\
\text { position by cultivating his/her friendship through } \\
\text { expensive gifts, entertaining or "personal favors" }\end{array}$ & 0.74 & 12.00 & 0.67 & 8.80 & \\
\hline $\begin{array}{l}\text { Gain information about an opponent's negotiating } \\
\text { position by trying to recruit or hire one of your } \\
\text { opponent's teammates (on the condition that the } \\
\text { teammate bring confidential information with him/ } \\
\text { her) }\end{array}$ & 0.73 & 11.77 & 0.85 & 12.11 & $\begin{array}{r}\text { Table IV. } \\
\text { Test of configural } \\
\text { invariance: multi-group }\end{array}$ \\
\hline & & & & (continued) & \\
\hline
\end{tabular}


EJM

$45,1 / 2$

Construct

Std.

The USA

Items

loading

Std.

Belgium

Information misrepresentation

144

Intentionally misrepresent information to your

opponent in order to strengthen your negotiating

arguments or position

Intentionally misrepresent the nature of

negotiations to your constituency in order to

protect delicate discussions that have occurred

Deny the validity of information, which your

opponent has, that weakens your negotiating

position, even though that information is true and valid.

Intentionally misrepresent the progress of

negotiations to your constituency in order to make

your own position appear stronger

Traditional competitive bargaining

Make an opening demand that is far greater than

what you really hope to settle for

Convey a false impression that you are in

absolutely no hurry to come to a negotiated

agreement, thereby trying to put time pressure on your opponent to concede quickly

Make an opening demand so high/low that it

seriously undermines your opponent's confidence in

his/her ability to negotiate a satisfactory settlement

Attacking opponent

Attempt to get your opponent fired from his/her

position so that a new person will take his/her place

Threaten to make your opponent look weak or

foolish in front of a boss or others to who he/she is

$\begin{array}{rrrr}0.63 & 9.83 & 0.74 & 10.52 \\ 0.63 & 9.66 & 0.57 & 7.74 \\ & & & \\ 0.70 & 11.28 & 0.61 & 8.34\end{array}$

0.70

11.27

0.55

7.44

accountable, even if you know that you will not

actually carry out the threat

Making false promises

Promise that good things will happen to your

opponent if he/she gives you what you want, even if

you know that you cannot (or will not) deliver these

things when the other's cooperation is obtained

In return for concessions from your opponent now,

offer to make future concessions which you know

you will not follow through on

Guarantee that your constituency will uphold the

settlement reached, although you know that they

will likely violate the agreement later

$\chi^{2}(\mathrm{df})$

Bentler-Bonnet Normed Fit Index (BNFI)

$0.78 \quad 12.81$

0.81

11.02

0.81

13.50

0.75

9.94

0.71

11.20

0.70

9.04

0.56

7.58

0.60

7.97

0.85

10.85

0.94

16.50

Bentler-Bonnet Non-normed Fit Index (BNNFI)

Comparative Fit Index (CFI)

Root Mean Square error of Approximation

(RMSEA)

0.83

15.04

0.92

13.59

0.82

14.77

0.68

9.06

0.70

11.61

0.57

7.35

1891.54

0.984

0.988

0.989

0.09

645

Table IV.

Note: *All $t$-values significant at the $p<0.05$ level 
discriminate well from one another. Our results indicated good discriminant validity for the constructs we used.

\section{Structural model and hypotheses testing}

With the acceptable measurement models across two countries, we estimated a two group structural model, allowing the structural paths to vary across countries. While multiple-group models are inherently difficult (Calantone et al. 2006), our results indicate a good fit. We present the results in Table VI. The chi-square for the model was significant $(\chi 2(\mathrm{df})=2190.23(688))$ but the other fit statistics, such as CFI $(0.987)$ and BNNFI (0.986), indicate that model fits the data well. The structural paths from Relativism to Opportunism, Deceitful Tendencies to Opportunism and Opportunism to each of the five negotiation tactics are significant. This model thus provides support for $H 1, H 2$ and $H 3$.

\begin{tabular}{|c|c|c|c|c|c|c|}
\hline \multirow[b]{2}{*}{ Fit statistics } & \multicolumn{6}{|c|}{ Constrained in each model } \\
\hline & $\begin{array}{l}\text { Factor } \\
\text { loadings }\end{array}$ & \multicolumn{2}{|c|}{$\begin{array}{l}\text { Factor loadings }+ \\
\text { factor variances }\end{array}$} & \multicolumn{3}{|c|}{$\begin{array}{c}\text { Factor loadings }+ \text { factor } \\
\text { variances }+ \text { factor covariances }\end{array}$} \\
\hline \multirow{5}{*}{$\begin{array}{l}\chi^{2}(\mathrm{df}) \\
\text { BNFI } \\
\text { BNNFI } \\
\text { CFI } \\
\text { RMSEA }\end{array}$} & 1937.347 (665) & \multicolumn{2}{|c|}{$1956.616(672)$} & \multicolumn{3}{|c|}{$2041.660(700)$} \\
\hline & 0.984 & \multicolumn{2}{|c|}{0.984} & \multicolumn{3}{|c|}{0.983} \\
\hline & 0.988 & \multicolumn{2}{|l|}{0.988} & \multicolumn{3}{|c|}{0.987} \\
\hline & 0.989 & \multirow{2}{*}{\multicolumn{2}{|c|}{0.989}} & \multicolumn{3}{|c|}{0.988} \\
\hline & 0.098 & & & \multicolumn{3}{|c|}{0.098} \\
\hline \multirow[b]{2}{*}{ Hypothesis } & \multirow[b]{2}{*}{ Structural paths } & & \multicolumn{2}{|c|}{ The USA } & \multicolumn{2}{|c|}{ Belgium } \\
\hline & & & $\begin{array}{l}\text { Std. } \\
\text { loading }\end{array}$ & $t$-value & $\begin{array}{l}\text { Std. } \\
\text { loading }\end{array}$ & $t$-value \\
\hline$H 1$ & Relativism (F1) $\rightarrow$ Op & unism (F3) & 0.25 & 2.65 & 0.37 & 2.74 \\
\hline H2 & Deceit $(\mathrm{F} 2) \rightarrow$ Opport & $n(\mathrm{~F} 3)$ & 0.43 & 4.13 & 0.74 & 3.87 \\
\hline H3 & $\begin{array}{l}\text { Opportunism }(\mathrm{F} 3) \rightarrow \\
\text { information gathering }\end{array}$ & bropriate & 0.88 & 7.20 & 0.72 & $(4.69$ \\
\hline H3 & $\begin{array}{l}\text { Opportunism (F3) } \rightarrow \\
\text { misrepresentation }(\mathrm{F} 5)\end{array}$ & mation & 0.84 & 7.22 & 0.98 & 5.17 \\
\hline$H 3$ & $\begin{array}{l}\text { Opportunism (F3) } \rightarrow \\
\text { bargaining (F6) }\end{array}$ & petitive & 0.44 & 5.07 & 0.65 & 4.47 \\
\hline$H 3$ & $\begin{array}{l}\text { Opportunism (F3) } \rightarrow \\
\text { opponents (F7) }\end{array}$ & king & 0.70 & 5.32 & 0.34 & 3.15 \\
\hline H3 & Opportunism (F3) $\rightarrow$ & promise (F8) & 0.96 & 9.64 & 0.84 & 5.14 \\
\hline & $\begin{array}{l}\chi^{2}(\mathrm{df}) \\
\text { Bentler-Bonnet Normed }\end{array}$ & Indey (BNFJ) & 2190.23 & 688 & & \\
\hline & $\begin{array}{l}\text { Bentler-Bonnet Non-no } \\
\text { (BNNFI) }\end{array}$ & Fit Index & $\begin{array}{l}0.902 \\
0.986\end{array}$ & & & \\
\hline & Comparative Fit Index & & 0.987 & & & \\
\hline & $\begin{array}{l}\text { Root Mean Square Err } \\
\text { Approximation (RMSE }\end{array}$ & & 0.095 & & & \\
\hline
\end{tabular}

Note: *All $t$-values significant at the $p<0.05$ level

Table VI. Structural model: US and Belgian samples 
EJM

$45,1 / 2$

146

To examine H4, we constrained the structural paths in the two country structural model to be equal across groups. Table VII presents the fit indices and the constrained cross-country structural paths for this model. The fit indices indicate $(\mathrm{CFI}=0.987$; BNNFI $=0.986)$ that the model fits the data well. Further, all the hypothesized paths are significant $(\phi<0.05)$. Lagrange Multiplier (LM) Tests in EQS (Bentler, 1992) did not suggest any significant cross-country differences in the structural model. Hence, $H 4$ is supported.

$H 5, H 6, H 7$ and $H 8$ suggested that US managers are less relativist, less deceitful, less opportunistic, and more critical of the questionable negotiation tactics than their Belgian counterparts. We tested these hypotheses using the latent means comparison test (Byrne, 2006, p. 261). Specifically, we designated the USA as a reference group and compared the Belgian sample to it. The key parameters in testing the hypotheses are the factor intercepts as they represent the latent mean values for the factors tested. Our analysis suggests that there was a significant difference between the US and Belgian managers on all the constructs. Table VIII contains the relevant statistics.

\section{Discussion}

In both countries, executives with higher relativistic tendencies are likely to be more opportunistic. Likewise, executives in both countries with deceitful tendencies are

\begin{tabular}{lcr}
\hline Structural paths (standardized) & Constrained path coefficient & $t$-value \\
\hline Relativism $\rightarrow$ Opportunism & 0.61 & 4.03 \\
Deceitful Tendencies $\rightarrow$ Opportunism & 0.41 & 6.17 \\
Opportunism $\rightarrow$ Inappropriate information gathering & 1.72 & 8.72 \\
Opportunism $\rightarrow$ Information misrepresentation & 1.83 & 9.56 \\
Opportunism $\rightarrow$ Competitive bargaining & 1.38 & 7.29 \\
Opportunism $\rightarrow$ Attacking opponents & 0.63 & 6.00 \\
Opportunism $\rightarrow$ False promise & 1.84 & 10.56 \\
$\chi^{2}($ df & 2210.618 & 695 \\
Bentler-Bonnet Normed Fit Index (BNFI) & 0.981 & \\
Bentler-Bonnet Non-normed Fit Index (BNNFI) & 0.986 & \\
Comparative Fit Index (CFI) & 0.987 & \\
Root Mean Square Error of Approximation (RMSEA) & 0.099 &
\end{tabular}

Table VII.
Constrained structural model

Note: *All $t$-values significant at the $p<0.05$ level

\begin{tabular}{lc}
\hline Construct & $z$-statistic* \\
\hline Relativism & 85.20 \\
Deceitful Tendencies & 34.24 \\
Opportunism & 41.86 \\
Inappropriate information gathering & 12.25 \\
Information misrepresentation & 17.68 \\
Competitive bargaining & 86.93 \\
Attacking opponent network & 13.63 \\
Making false promises & 12.38
\end{tabular}

Table VIII.

Latent mean comparison

Note: *All values significant at the $p<0.05$ 
likely to be more opportunistic. Opportunism is likely to give rise to each of the unethical negotiation tactics for both samples. While the theoretical relationships among constructs were not found to differ across countries, there were differences in the levels of the constructs. Specifically managers in the USA scored in a more ethical direction for all measures.

To explore the possibility that differing methods between the countries produced some of our results, we followed the recommendations of Podsakoff et al. (2003) and used Harman's single-factor test as well as confirmatory factor analysis (CFA) to test for method factor. Additionally, we tested a multifactor measurement model and a measurement model with an additional method factor added for each of the countries; inclusion of these method factors did not significantly improve the model fit (Carlson and Kacmar, 2000).

\section{Theoretical and managerial implications}

Drawing on the empirical findings within the USA, we show how relativism and deceitful tendencies may serve as antecedents of opportunism. We show that opportunism can be triggered by intrinsic orientations in competitive negotiation process (Bonoma, 1976) across different cultural contexts, which also explains how intrinsic characteristics may lead an individual to a conscious decision to behave opportunistically (John, 1984). This contributes to the negotiation ethics literature in an international context.

Next, we add to the new perspective on opportunism (Malshe et al., n.d.) by testing it within a cross-country context. This is particularly important with respect to deceitful tendencies, which has received limited conceptual attention in the negotiation ethics literature. Specifically, we do not focus on reasons for or frequency of deceit but view deceitful tendency as a personality characteristic that varies across individuals in the international context. In doing so, this study not only examines this understudied construct but also situates it within the broader cross-cultural negotiation ethics literature.

This work would be valuable if only as a validation of the various scales used in the Belgian context. In addition, it contributes to the growing body of research related to the emergence of global business ethics. Viewed together, our contribution thus lies in exploring the role of relativism and deceitful tendency in the Belgian context for the first time and offering an empirical comparison with that in the USA.

When viewed holistically, our results suggest that American and Belgian managers may exhibit divergent levels of deceitful tendencies, relativism, opportunism and perceptions of unethical negotiation tendencies. Our results, however, also show that the impact of their deceitful tendencies and relativism on opportunism and that of opportunism on the unethical negotiation practices shows convergence in terms of the nature and strength of the relationships. Thus, this paper offers an important perspective on the convergence versus divergence controversy (Bond and King, 1985), which constitutes its third contribution.

Our work highlights an important distinction that should be made in this debate. That distinction is between the levels of various ethical constructs and their impact on other variables. In other words, between the level or amount of a construct such as relativism and its impact on other constructs such as opportunism. While we believe there are a variety of reasons to expect levels of constructs to converge, diverge or
Deceitful tendencies 
EJM

$45,1 / 2$

148 crossverge among different populations, we are skeptical that the structural relationships among those constructs should. If such variances are found, we are inclined to expect it is a result of an incomplete nomological network; in other words, that an important moderating variable has been neglected.

Our findings may help managers in many ways. First, our work suggests that those involved in international negotiations must simultaneously make two assessments when it comes to their counterparts. They must first gauge the ethical stances of their negotiation partners and then understand how those stances ultimately translate into bargaining behavior; in other words, they must be able to say to themselves "if my negotiating partner is opportunistic, then they are likely to try to make false promises; therefore, I need to build in additional verification and governance measures".

It is plausible that US managers may mistakenly conclude that their Belgian negotiation partners are highly opportunistic, when, in fact, within the Belgian context, they are not. This may force the US managers to proceed with undue caution. US managers, however, should be aware that higher levels of relativism and deceitful tendencies among Belgian managers may lead to higher levels of opportunism, just as they would in the USA. And, as among US managers, higher levels of opportunism will lead to a greater likelihood to engage in unethical negotiation tactics.

The US manager must also be sensitive to the differences due to the broader cultural context. Conversely, to Belgian managers their US counterparts might all appear to have very low levels of relativism, deceitful tendencies and opportunism. As a result, their expectation might be that US managers might be easy marks in their negotiations. Belgians might therefore be inclined to enact insufficient safeguards against unethical behavior. They need to understand that, while US managers might have lower levels of opportunism, etc, there is still variance and that relatively opportunistic US managers may still try to take advantage of them; just as Belgian managers would.

Taken as a whole, our research suggests that, contrary to traditional transaction cost analysis, managers may not act opportunistically in negotiations with their trading partners simply given that it is feasible and profitable to do so. The profitable feasibility of opportunistic behavior should instead be viewed as a necessary but not sufficient condition for such behavior. In addition to those external state conditions, we see that the likelihood of opportunistic behavior increases as relativism increases, and as the tendency to act deceitfully increases. Thus, in addition to the governance structures typically prescribed to mitigate opportunism, we also observe that, given the right business partner, transaction cost may remain low even in the absence of explicit governance structures.

What is the appropriate level of external control mechanism required in a business relationship? Our research suggests that managers would be well advised to gauge the level of relativism and deceitful tendencies of their negotiation partners prior to contracting with them. Business partners, regardless of country, that are less relativistic and who have fewer deceitful tendencies may be engaged without over emphasis on governance structures that, being unnecessary, would have the unintended consequence of raising transaction costs. However, engaging a highly relativistic business partner who has deceitful tendencies without the appropriate governance structures will raise transaction costs via the higher levels of opportunism they will manifest. 
While managers have long taken advantage of informal opportunities to casually take stock of their negotiation partners, the present research highlights the critical importance of doing so and suggests that more formal mechanisms be put in place. We leave sorting out what exactly those mechanisms might be to other researchers and other studies.

Limitations and direction for future research

Before concluding, we recognize some limitations of the study. Our Belgian sample was relatively small and method of data collection varied between the two countries. Therefore, some of our cross-country conclusions should be treated as tentative and our Belgian findings perhaps more exploratory in nature.

Also the RMSEAs in our analyses were generally above 0.09, and chi-squares generated in the test of measurement invariance deteriorated as we constrained the model, both potential causes for concern. In addition, one may argue that the construct reliabilities and average variances extracted we report in Table IV are less than optimal.

Both the USA and Belgium have cultures rooted in Northern and Western Europe, are democratic, and have free-market economies. This might explain why we found similar relationships among the constructs. Further, contextual factors such as the nature of the prior inter-firm relationship or interpersonal relationships between the negotiators could foster or hinder opportunism and the use of particular negotiation tactics. We did not include these factors in our analysis.

Last, we have not examined how exposure to or evidence of deceitful tendencies, relativism and opportunism from a negotiation partner may affect one's own stance vis-à-vis opportunism and those same behaviors, either within the US, within Belgium or across the two countries. Future research may examine how other constructs such as idealism interact with relativism to moderate opportunism. Testing our model in different country contexts also remains a fruitful area for future research.

\section{References}

African Business (2004), "Lesotho corruption appeal backfires", African Business, Vol. 299, p. 8.

Al-Khatib, J.A., Malshe, A. and AbdulKader, M.R. (2008), "Perception of unethical negotiation tactics: a comparative study of US and Saudi managers", International Business Review, Vol. 17, pp. 78-102.

Al-Khatib, J.A., Stanton, A.D. and Rawwas, M.Y.A. (2005b), "Ethical segmentation of consumers in developing countries: a comparative analysis", International Marketing Review, Vol. 22 No. 2, pp. 225-46.

Al-Khatib, J.A., Vollmers, S.M. and Liu, Y. (2007), "Business-to-business negotiating in China: the role of morality”, Journal of Business \& Industrial Marketing, Vol. 22 No. 2, pp. 84-96.

Al-Khatib, J.A., Rawwas, M.Y.A., Swaidan, Z. and Rexeisen, R.J. (2005a), “The ethical challenges of global business-to-business negotiations: an empirical investigation of developing countries' marketing managers", Journal of Marketing Theory and Practice, Vol. 13 No. 4, pp. $46-60$.

Armstrong, J.S. and Overton, T.S. (1977), "Estimating non-response bias in mail surveys", Journal of Marketing Research, Vol. 14 No. 3, special issue: Recent Developments in Survey Research, pp. 396-402.

Deceitful tendencies 
EJM

$45,1 / 2$

Aulakh, P.S., Kotabe, M. and Sahay, A. (1996), "Trust and performance in cross-border marketing partnerships: a behavioral approach", Global Perspectives on Cooperative Strategies, Journal of International Business Studies, Vol. 27 No. 5, pp. 1005-32.

Bagozzi, R.P. (1995), "Reflections on relationship marketing to consumer markets", Journal of the Academy of Marketing Science, Vol. 23, pp. 272-7.

Bentler, P. (1992), EQS Structural Equations Program, BMDP Statistical Software, Los Angeles, CA.

Bond, M.H. and King, A.Y.C. (1985), "Coping with the threat of westernization in Hong Kong", International Journal of Intercultural Relations, Vol. 9 No. 4, pp. 351-64.

Bonoma, T.V. (1976), "Conflict, cooperation and trust in three power systems", Behavioral Science, Vol. 21 No. 6, pp. 499-514.

Byrne, B.M. (2003), "Testing for equivalent self-concept measurement across culture: issues, caveats, and application. International advances in self research”, in Marsh, H.W., Craven, R.G. and McInerney, D. (Eds), Vol. 1, Information Age, Greenwich, CT.

Byrne, B.M. (2006), Structural Equation Modeling with EQS: Basic Concepts, Applications, and Programming, Vol. 2, Lawrence Erlbaum Associates, Mahwah, NJ.

Calantone, R.J., Kim, D., Schmidt, J.B. and Cavusgil, S.T. (2006), "The influence of internal and external firm factors on international product adaptation strategy and export performance: a three-country comparison”, Journal of Business Research, Vol. 59 No. 2, pp. 176-85.

Carlson, D.S. and Kacmar, K.M. (2000), "Work-family conflict in the organization: do life role values make a difference?", Journal of Management, Vol. 26, pp. 1031-54.

Central Intelligence Agency (CIA) (2007), World Factbook, CIA, Washington, DC, available at: www.cia.gov/library/publications/the-world-factbook/geos/be.html (accessed 26 August 2007).

Christie, R. and Geis, F.L. (1970), Studies in Machiavellianism, Academic Press, New York, NY.

Cramton, P.C. and Dees, J.G. (1993), "Promoting honesty in negotiation: an exercise in practical ethics", Business Ethics Quarterly, Vol. 3 No. 4, pp. 359-94.

Dwyer, F.R. and Oh, S. (1988), "A transaction cost perspective on vertical contractual structure and interchannel competitive strategies”, Journal of Marketing, Vol. 52 No. 2, pp. 21-34.

Ferrell, O.C. and Gresham, L.G. (1985), "A contingency framework for understanding ethical decision making in marketing", Journal of Marketing, Vol. 49, pp. 87-96.

Forsyth, D.R. (1980), "A taxonomy of ethical ideologies", Journal of Personality and Social Psychology, Vol. 39 No. 1, pp. 175-84.

Forsyth, D.R. (1992), "Judging the morality of business practices: the influence of personal moral philosophies", Journal of Business Ethics, Vol. 11 Nos 5/6, pp. 461-70.

Hagarty, W.H. and Sims, H. (1978), "Some determinants of unethical decision behavior: an experiment", Journal of Applied Psychology, Vol. 63, p. 451.

Helper, S. and Levine, D.I. (1992), "Long-term supplier relations and product-market structure", Journal of Law, Economics \& Organization, Vol. 8 No. 3, pp. 561-81.

Hofstede, G. (1980), "Angola coffee - or the confrontation of an organization with changing values in its environment”, Organization Studies, Vol. 1, pp. 21-40.

Horn, J.L. and McArdle, J.J. (1992), “A practical and theoretical guide to measurement invariance in aging research", Experimental Aging Research, Vol. 18, Fall-Winter, pp. 117-44.

Hunt, S.D. and Chonko, L.B. (1984), "Marketing and machiavellianism", Journal of Marketing, Vol. 48, pp. 30-42. 
Hunt, S.D. and Morgan, R.M. (1995), "The comparative advantage theory of competition”, Journal of Marketing, Vol. 59 No. 2, pp. 1-15.

Hunt, S.D. and Vitell, S.J. (1986), "A general theory of marketing ethics", Journal of Macromarketing, Spring, pp. 5-16.

Hunt, S.D. and Vitell, S.J. (1992), "The general theory of marketing ethics: a retrospective and revision”, in Quelch, J. and Smith, C. (Eds), Ethics in Marketing, Richard D. Irwin, Chicago, IL.

Hunter, J.E., Gerbing, D.W. and Boster, F.J. (1982), "Machiavellian beliefs and personality: construct invalidity of the machiavellianism dimension", Journal of Personality \& Social Psychology, Vol. 43, pp. 1293-305.

Husted, B.W. (1999), "Wealth, culture, and corruption”, Journal of International Business Studies, Vol. 30, pp. 339-59.

International Construction (2004), "Global anti-corruption drive", International Construction, Vol. 43 No. 2, p. 7.

Jeurissen, R.J.M. and van Luijk, H.J.L. (1998), "The ethical reputations of managers in nine EU-countries: a cross-referential survey”, Journal of Business Ethics, Vol. 17 No. 9, pp. 995-1005.

John, G. (1984), "An empirical investigation of some antecedents of opportunism in a marketing channel”, Journal of Marketing Research, Vol. 21 No. 3, pp. 278-89.

Joshi, A.W. and Arnold, S.J. (1997), "The impact of buyer dependence on buyer opportunism in buyer-supplier relationships: the moderating role of relational norms", Psychology \& Marketing, Vol. 14 No. 8, pp. 823-45.

Kale, S.H. and McIntyre, R.P. (1991), "Distribution channel relationships in diverse cultures", International Marketing Review, Vol. 8 No. 3, pp. 31-45.

Lax, D.A. and Sebenius, J.K. (1986), "Measure of negotiation", Negotiation Journal, Vol. 2, pp. 73-92.

Lewicki, R. and Robinson, R. (1998), "Ethical and unethical bargaining tactics: an empirical study”, Journal of Business Ethics, Vol. 17, pp. 665-82.

Lewicki, R. and Stark, N. (1996), "What is ethically appropriate in negotiations? An empirical examination of bargaining tactics", Social Justice Research, Vol. 9 No. 1, pp. 69-95.

Malshe, A., Al-Khatib, J. and Sailors, J. (n.d.), "Business-to-business negotiations: the role of relativism, deceit, and opportunism”, Journal of Business-to-Business Marketing, forthcoming.

Mitchell, R.W. (1986), “A framework for discussing deception”, in Mitchell, R.W. and Thompson, N.S. (Eds), Deception: Perspectives on Human and Nonhuman Deceit, State University of New York Press, Albany, NY, pp. 3-40.

Newstead, S.E., Franklyn-Stokes, A. and Armstead, P. (1996), "Individual differences in student cheating”, Journal of Educational Psychology, Vol. 88, pp. 229-41.

Nunnally, J.C. (1978), Psychometric Theory, McGraw-Hill, New York, NY.

Podsakoff, P.M., MacKenzie, S.B., Lee, J. and Podsakoff, N.P. (2003), "Common method biases in behavioral research: a critical review of the literature and recommended remedies", Journal of Applied Psychology, Vol. 88 No. 5, pp. 879-904.

Ranchhod, A. and Zhou, F. (2001), "Comparing respondents of e-mail and mail surveys: understanding the implications of technology", Marketing Intelligence \& Planning, Vol. 19 No. 4, pp. 254-62. 
EJM

$45,1 / 2$

152

Rawwas, M.Y.A., Al-Khatib, J.A. and Vitell, S.J. (2004), “Academic dishonesty: a cross-cultural comparison of US and Chinese marketing students", Journal of Marketing Education, Vol. 26 No. 1, pp. 89-100.

Rawwas, M.Y.A., Swaidan, Z. and Al-Khatib, J. (2006), "Does religion matter? A comparison study of the ethical beliefs of marketing students of religious and secular universities in Japan”, Journal of Business Ethics, Vol. 65 No. 1, pp. 69-86.

Robinson, R.J., Lewicki, R.J. and Donahue, E.M. (2000), "Extending and testing a five factor model of ethical and unethical bargaining tactics: introducing the SINS scale", Journal of Organizational Behavior, Vol. 21 No. 6, pp. 649-64.

Sakalaki, M., Richardson, C. and Thepaut, Y. (2007), "Machiavellianism and economic opportunism”, Journal of Applied Social Psychology, Vol. 37 No. 6, pp. 1181-90.

Scott, E.D. and Jehn, K.A. (1991), "Ranking rank behaviors: a comprehensive situation-based definition of dishonesty”, Business Society, Vol. 38 No. 3, pp. 296-325.

Steenkamp, E.M.H.-B. and Baumgartner, H. (1998), "Assessing measurement invariance in cross-national consumer research", The Journal of Consumer Research, Vol. 25 No. 1, pp. 78-90.

Stump, R.L. and Heide, J.B. (1996), “Controlling supplier opportunism in industrial relationships”, Journal of Marketing Research, Vol. 33, pp. 431-41.

Triandis, H.C. (2001), "Culture and deception in business negotiations: a multilevel analysis", International Journal of Cross Cultural Management, Vol. 1 No. 1, pp. 73-90.

Van Kenhove, P., Vermeir, I. and Verniers, S. (2001), "An empirical investigation of the relationships between ethical beliefs, ethical ideology, political preference and need for closure”, Journal of Business Ethics, Vol. 32 No. 4, pp. 347-61.

Vitell, S., Nwachukwu, S. and Barnes, J. (1993), "The effects of culture on ethical decision making: an application of Hofstede's typology", Journal of Business Ethics, Vol. 12 No. 10, pp. $753-60$.

Volkema, R.J. (2004), "Demographic, cultural, and economic predictors of perceived ethicality of negotiation behavior: a nine-country analysis", Journal of Business Research, Vol. 57, pp. 69-78.

Volkema, R.J. and Fluery, M.T. (2002), "Alternative negotiating conditions and the choice of negotiation tactics: a cross-cultural comparison", Journal of Business Ethics, Vol. 36, pp. 381-98.

Wathne, K.H. and Heide, J.B. (2000), "Opportunism in interfirm relationships: forms, outcomes, and solutions", Journal of Marketing, Vol. 64 No. 4, pp. 36-51.

Williamson, O.E. (1975), Markets and Hierarchies, Analysis and Antitrust Implications: A Study in the Economics of Internal Organization, Free Press, New York, NY.

\section{Corresponding author}

Jamal A. Al-Khatib can be contacted at: jaalkhatib@stthomas.edu

To purchase reprints of this article please e-mail: reprints@emeraldinsight.com Or visit our web site for further details: www.emeraldinsight.com/reprints 